\title{
THE DIGITAL ATELIER: HOW SUBTRACTIVE TECHNOLOGIES CREATE NEW FORMS
}

Professor Jeremy Gardiner

Senior Research Fellow,

Department of History of Art and Screen Media,

Birkbeck, University of London, 43, Gordon Square,

Bloomsbury, London WC1H OPD UK

mail@jeremygardiner.co.uk

www.technocultures.org

The Digital Atelier: For 50 years artists have been utilising the convergence and combination of different technologies to produce visually and intellectually challenging artworks. These artists create compelling artefacts that engage the pragmatics of technology and the free invention of art and bring them to a successful synthesis. A close examination of work from the past and present reveals how advanced digital design methods and subtractive fabrication processes have been used to make physical things from virtual data.

\section{INTRODUCTION}

The idea of a Digital Atelier comes from the French term for studio. Since the 1960s [1] the conceptual path of a small group of painters, printmakers and sculptors was considerably altered and redefined by the use of the computer. These artists began forging new forms utilising digital design systems and fabrication processes and have produced work that uses both subtractive and additive technologies. Their research encompasses the scientific exploration of materials, the development and use of new technologies, the cross-fertilisation of old and new technologies and the creation of new forms.

\section{TECHNIQUES AND TECHNOLOGIES}

The term solid freeform fabrication is applied to a range of techniques for manufacturing solid 3D objects directly from Computer Aided Design (CAD) data. To make sense of the many techniques and technologies used today we can divide them into either subtractive or additive processes.

Subtractive fabrication is the term given to any fabrication process where material is taken away or reduced from a solid in order to reveal a new shape. This subtraction can take place using any combination of tooling techniques such as drills, lathes, and grinders, and more recently lasers and high-pressure water jets. With additive fabrication, the machine reads data from a CAD drawing and lays down successive layers of liquid or powder and in this way builds up the model from a series of cross sections.

This paper will focus on artists using subtractive technologies. A second paper examining additive technologies will be delivered as part of Digital Continuities: From the History of Digital Art to Contemporary Transmedial Practices at the Association of Art Historians conference from 15 $5^{\text {th }}-17$ th April 2010 at the University of Glasgow. 
The following examples echo the forms of the past whilst utilising the latest technologies. Using the concept of 'Ideas before their time - Connecting the past and present in Computer Art' I am going to take a look at the work of two pioneering artists working with subtractive technologies: Robert Mallary and Richard Hamilton and how they have influenced the work of two specific contemporary artists; Bengtsson and Delvoye in the case of Mallary, and Grossman and Shafiei in the case of Hamilton.

\section{MALLARY, BENGTSSON AND DELVOYE}

Bengtsson and Delvoye laser cut a variety of sheet materials from plywood to corten steel to create their volumetric sculptural artworks. In 1968 the artist Robert Mallary began to experiment with computer sculpture, he manufactured Quad II and Quad III. To create these sculptures he developed his ideas on sequential contour projection and used them in the creation of sculptural computer forms [2]. The computer program he developed with his colleagues was called TRAN2, described in the following extract:

"TRAN2 is a computer graphics program with twenty sub-routines to generate sculpture. The program presupposes a means of compiling form description data for use by the computer. This is done by breaking down the solid into a regular series of parallel cross sections, or contour "slices," which are then graphed and digitized as X, Y and $\mathrm{Z}$ coordinates and transferred to punch cards. A sequence of mathematical transformation procedures is brought to bear on the contour sections whereby the computer, in effect, models and reshapes the contour sections into an original sculpture. The computer plotter reproduces a series of perspective views of the generated form together with a complete set of the transformed contour sections. These are used as patterns to complete the sculpture in some appropriate material."

Mallary considered the computer as an intelligence and information amplification device which could be linked synergistically with the unique, creative capacities of the human mind for creative activity, surpassing either human or machine capabilities functioning independently.

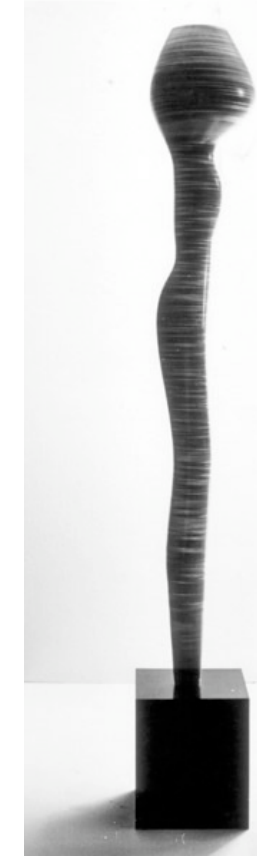


Figure 1. Quad II. 1968. Material: Plywood. Robert Mallary

The information for the contour slices in Fig. 2 was transferred to computer punch cards as described before. The plotter produced a series of perspective views which Mallary called 'Computer transformation templates'. These 2D slices were used as patterns for cutting the final sculpture from laminated wood veneer.

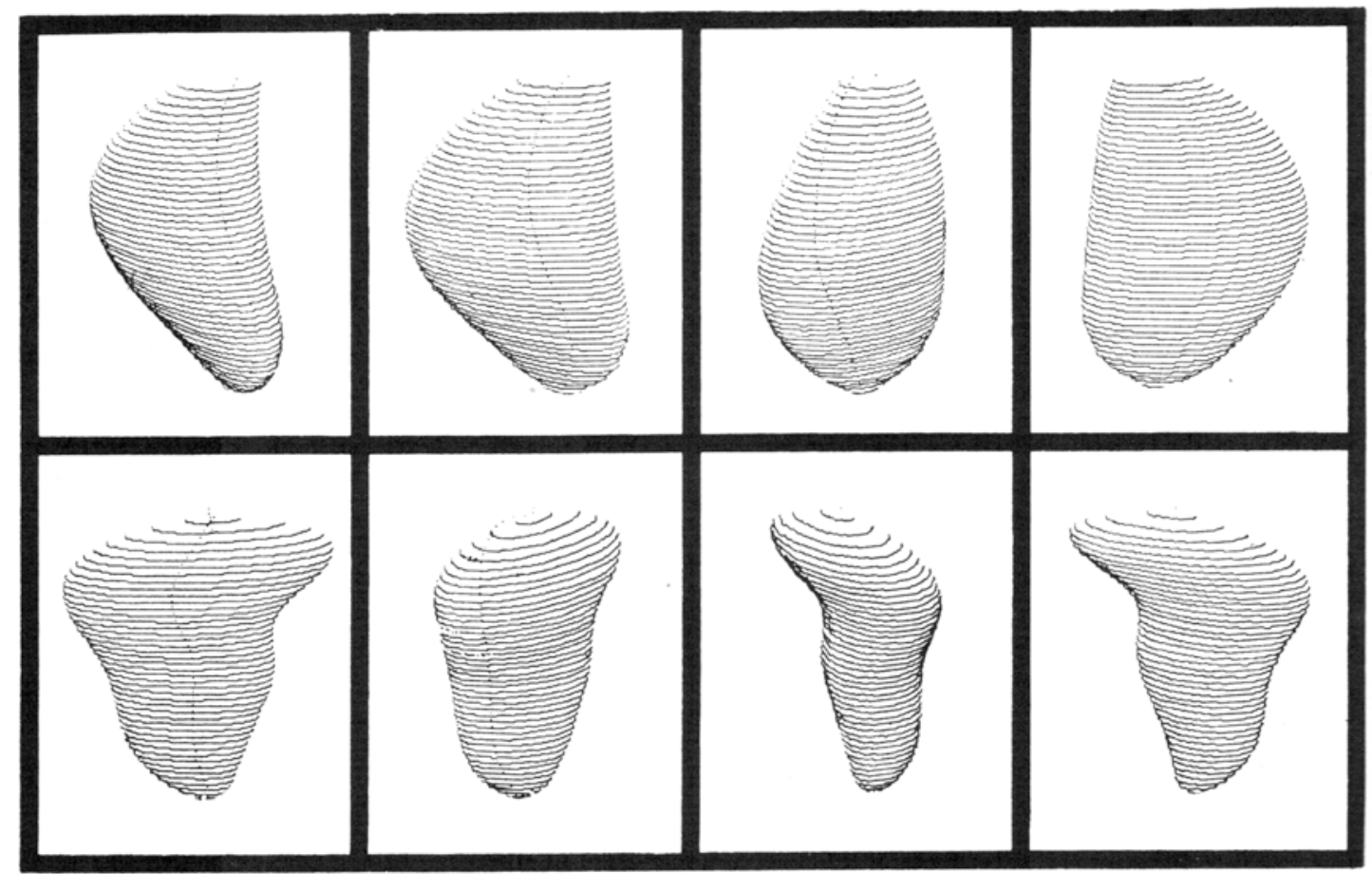

Figure 2. Computer transformation templates. 1968. Robert Mallary.

Mallary began using rapid prototyping for his sculptures in the 1960s and since that time increasing numbers of visual artists have used rapid prototyping, as prices of hardware and software have dropped and performance, user interface and output technology have improved dramatically.

The following contemporary artists employ lasers to cut the component parts of their work using paper, wood steel and plastics. A laser is an amplifier of light, focusing it into an intense beam that can burn, melt and evaporate the material it encounters and because the cutting tool is a beam of light it can move very quickly and makes cuts as fine as the focus of the beam.

Mathius Bengtsson uses materials that are both natural and manufactured, each material seems to be carefully chosen to highlight the sinuous quality of the final design. 'The Slice chair was constructed with the same adeptness an architect would employ to create a topological map of the landscape, evoking the illusion of a piece of furniture cut away from a cliff face and scaled to human proportions.' Bradley Quinn, in Scandinavian Style [3]. First drawn by hand and later modelled in clay, the Slice chair combines organic shapes with cutting-edge technology. Slice is constructed as an assemblage of horizontal cross-sections that stack together into a uniquely lateral 
profile. Laser-cut to a thickness of only $3 \mathrm{~mm}$, each individual layer resembles a twodimensional abstraction more than it does a hi-tech element. Although the process was inspired by rapid prototyping methods, Bengtsson worked with more traditional materials. His starting point was to create a new form by using clay, which he then sliced in horizontal layers and manipulated digitally. The result was a surprising shape that blurred the distinctions between armrests, backrest, legs and frame.
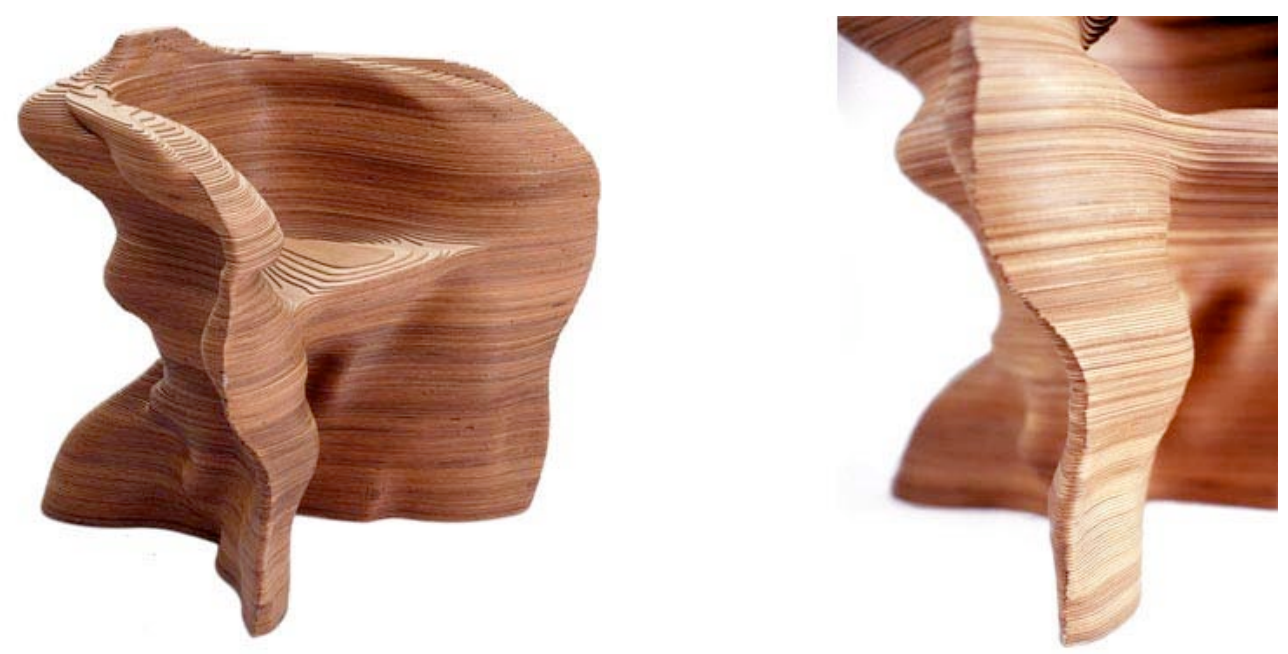

Figure 3. Slice Chair. Material: Plywood. 1999. Mathius Bengtsson

'It has such a strong aerodynamic feel that it could be an aircraft or a Formula One racing car.' Corinne Julius, in the Evening Standard

Conceived as a single, sweeping curve, the 'Slice chaise longe' comprises a contouring backrest that arcs forward to support the legs and feet. Crafted in ninety nine individual layers, regular spaces between each allows the eye to travel far beyond the chaise's structure. As with the aluminium Slice chair, Bengtsson used transparency as a device to deconstruct the conventional parts of a chaise longe. Bengtsson's technique makes every aspect of the chaise visible in a single glance, and breaks down the density of its complex surface area. The 'Slice chaise longe' echoes the form of Mallary's 'Quad I' and 'Quad II' but in the horizontal plane. 


\section{CAT 2010 London Conference $\sim 3^{\text {rd }}$ February \\ Jeremy Gardiner}
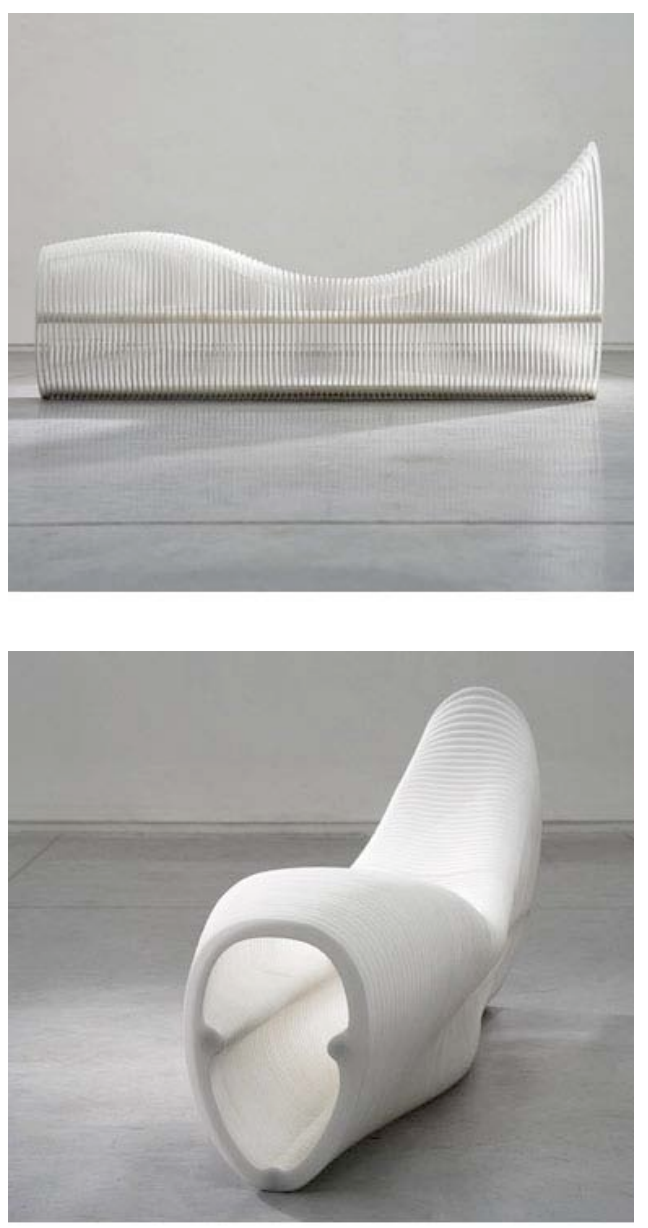

Figure 4. Slice Chaise. Material: Acrylic. 2000. Mathius Bengtsson

Wim Delvoye takes laser-cutting in steel to a new scale with his highly detailed sculptures in ornate patterns referencing the industrial revolution and gothic and Victorian architecture. 


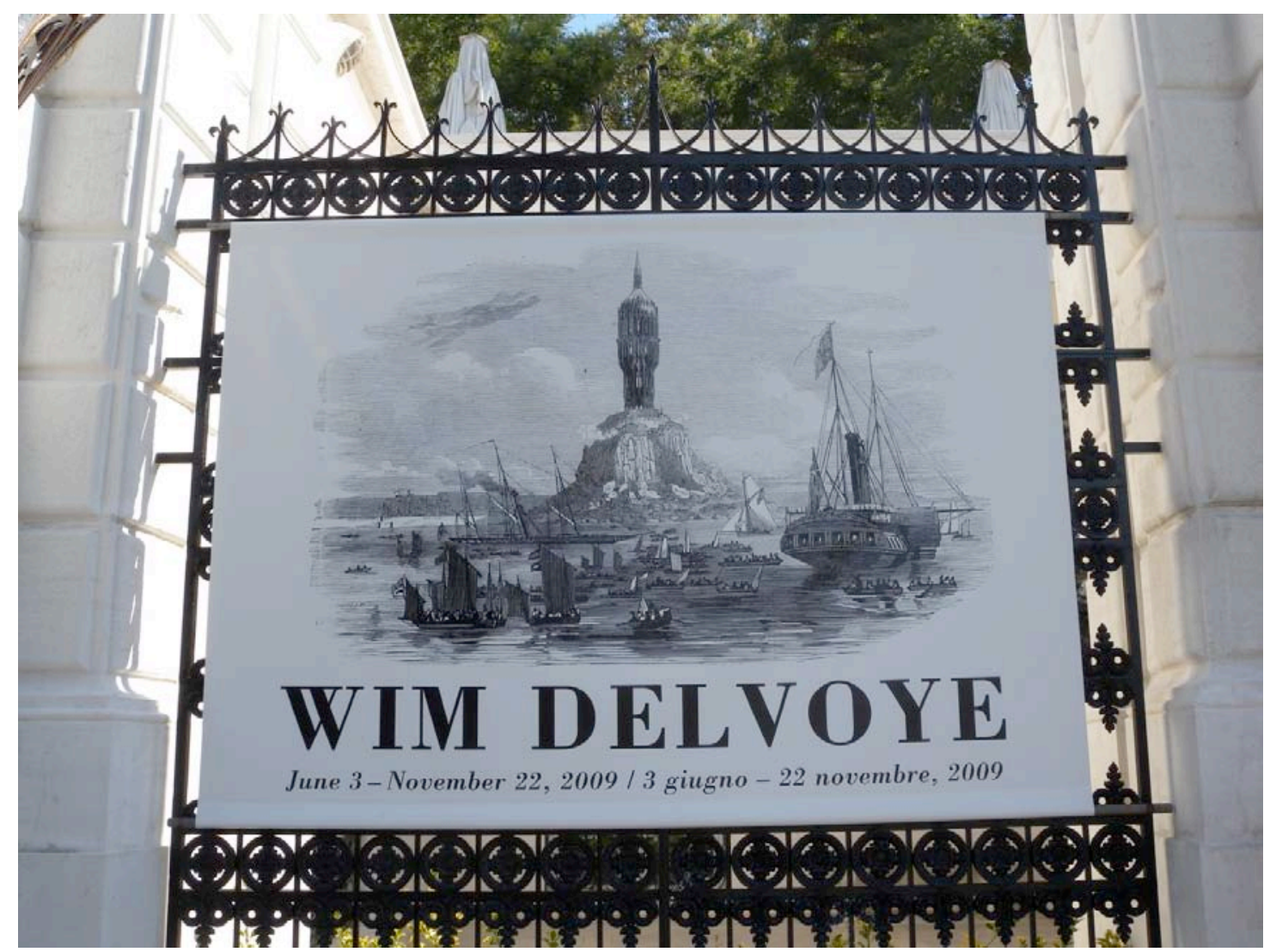

Figure 5. Wim Delvoye. Peggy Guggenheim Museum 2009.

Wim Delvoye's artistic practice draws on the notion of the attraction of binary opposites: the past and the present, the triumph of ornamentation over functionality [4]. The Peggy Guggenheim collection presented Wim Delvoye's latest creation, 'Torre': a corten steel tower, with ogival windows, tracery and turrets in the international gothic style, on the terrace of palazzo Venier dei Leoni, overlooking the grand canal in Venice in 2009. 

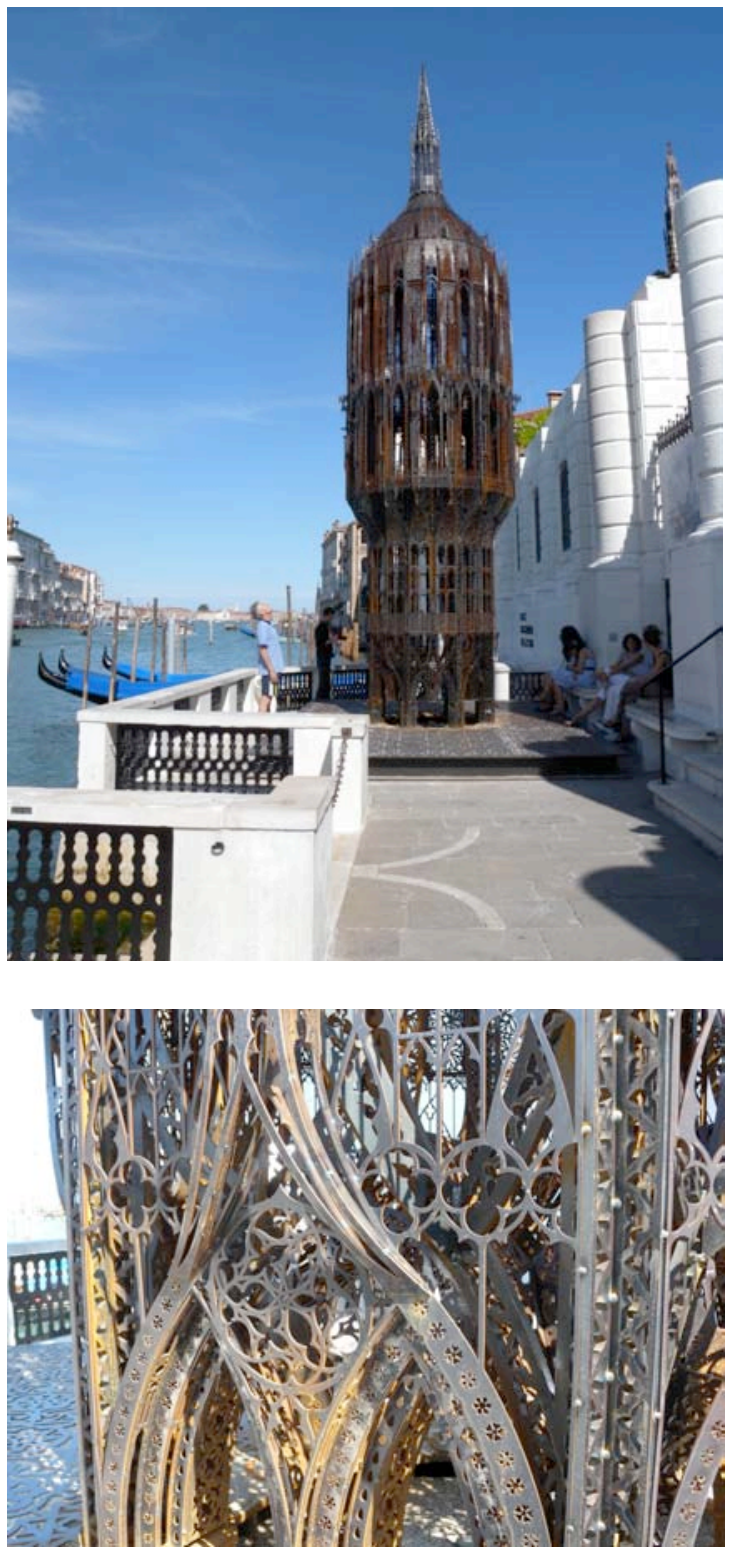

Figure 6. Torre. Corten steel. 2009. Wim Delvoye. Peggy Guggenheim Museum.

"I tried to integrate the tower with the building, but the architecture of the building is Neo-Classical. My project is another style completely. The way I designed it is also very unorthodox - from the top down rather than from the base to the peak.

I want every detail to be perfect. My design team has incorporated the Gothic style and Gothic Revival into the tower. These are architects who have worked with me for years and totally understand what I want. I've constructed other towers, but they were mere exercises in relation to this one. Last year I exhibited a couple of 6-meter-tall [20-foot] maquettes in Moscow and Basel, but the tower for the Peggy Guggenheim Collection is a scale model for a tower that I hope someday to build. It's one-to-four, a quarter of the size, which is still huge.

I've designed towers 80 meters [262 feet] high. One is 325 meters [1,066 feet] high to match the Eiffel Tower. They remain maquettes, but with the Venice tower I'm very 
motivated to push the design into reality because I'm satisfied with what we've done. It starts where Gothic stopped. We somehow ate it all, we assimilated it, and now we've done a Gothic style that has never been done. It's like we've continued a long tradition, but we are not just copying other people-we're inventing.

The tower is Cor-Ten steel, which is laser-cut, folded and welded. It's layered and very sculptural. The surface will be rusted, but we'll varnish it to keep it from bleeding into the stone of the historical building. By making it in this steel we can do things that the Gothic builders couldn't do. Some of those things are more beautiful in steel than in stone.

The designs are computer-generated. Since 2000 I've created 3-D images so I can see how my works might look in real life. We have several different programs and we play with their limitations. I'm always reminding my staff about the great cathedrals of Strasbourg, Cologne, Canterbury and Paris, which weren't built with computers, cameras and helicopters". Wim Delvoye

\section{HAMILTON, GROSSMAN AND SHAFIEI}

Richard Hamilton's interest in technology began with his reading Giedion's 'Mechanization takes Command'. The impact of technology was also the theme of Hamilton's exhibition 'Man, Machine and Motion', at the Hatton Gallery of Newcastle University and the ICA in 1955.

From 1951 to 1963 Hamilton made perspective drawings leading to the 1964 print,'Five Tyres Abandoned' In an issue of a magazine called Technique et Architecture published around 1951, there was an illustration of five tyres in a row. On the centre of each tread was an oval panel labelling it with a date - 1902, 1905 and so on to 1950.

"In 1963, I began to make a perspective drawing of the subject. I proposed to make a print; an embossed relief, printed blind, so that the effect would be of the varied treads of the five tyres pressing up from the back of the paper - but in perspective. After working for a good many weeks it became clear that to continue in the rigorously accurate manner that alone made the task worthwhile would require such an abundance of time that I would have to consider whether the result could possibly merit such devotion. It was then I regretfully decided not to complete the drawing, and 'Five tyres abandoned' became the title of the 1964 print." Richard Hamilton.

The project had been revived in 1970 when an American art dealer, Carl Solway, publisher of EYE Editions, offered to find a US computer programmer interested in plotting the perspective drawing with a computer. Sherill F. Martin, manager of computer animation at Kaye Instruments, organised the computer formulation of the perspective drawing using a general FORTRAN programme called CAPER (Computer Aided Perspective).

"The uses to which the computer has been put by artists most often develop out of properties peculiar to that device which enable it to use a set of instructions to effect transformations of a given image, or develop sequences of kinetic patterns. There is a tendency to ask it to perform what it most likes doing, or at least what it does most fluently, so we have to come to recognise a computer graphics style. [5] The use of a 
computer to make a conventional perspective projection puts no claim on its capabilities as an image creator - that is to say, the stylish qualities are not prompted by the tool. This kind of problem might have been posed by anyone since Piero della Francesca and its solution can be precisely forseen. What the computer provides is an inhuman speed which makes possible the formulation of a complex perspective image in its purest terms." Richard Hamilton

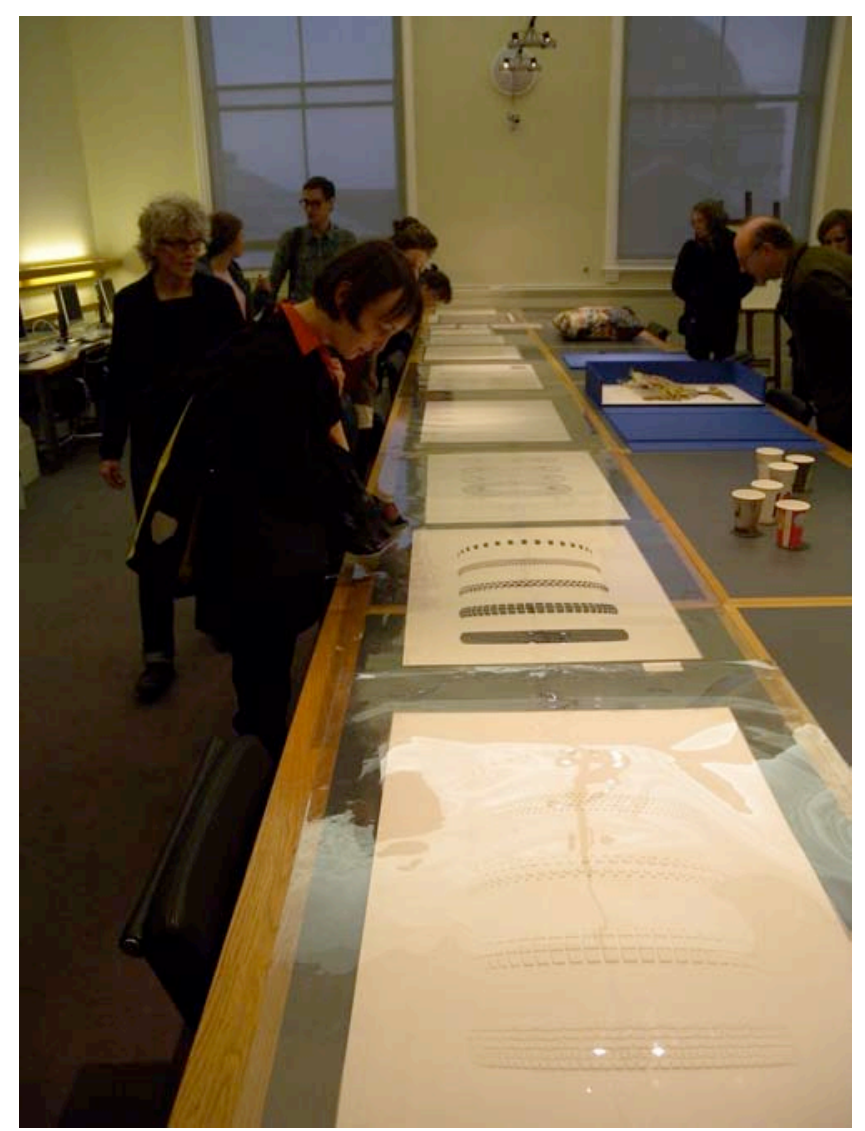

Figure 7. Five Tyres. 1972. Printed by Frank Kicherer, Stuttgart. The relief cast was made by Hartmut Freilinghaus of Hamburg. Richard Hamilton. V\&A print room '3D for Print' symposium March 2009.

"Major computer programmes usually have wider applications than that of giving an answer to the specific problem in hand. CAPER (computer aided perspective), itself an extension of CALD (computer aided line drawing), by S E Anderson of Syracuse University, May 1967, is a general programme, written in FORTRAN. This offers the essential notions as to how instructions to the plotter may be stated, together with card coded commands which provide the potential for the generation of any line- drawing. Sherill Martin received the data and proceeded to inform CAPER so that it would tell a plotter how to draw the required perspective. A series of encoded messages was then converted into a deck of punched cards. An IBM 36075 computer read the deck and generated signals on a magnetic tape to control the movements of a pen on a drafting machine. In this case a Calcomp 763 was used, which co-ordinates rotary movements of the paper with lateral movements of the pen along the axis of the cylinder to produce any figure. 
At this stage the original idea of producing an embossed print on paper was modified to a proposal to cast the relief to the treads integrally with a sheet of cold-curing rubber. I filled in the linear drawing by hand with the intention of etching a metal plate to serve as a mould. Etching proved unsatisfactory, so the mould was mechanically engraved in a brass plate. Machine cutting permitted a variation of relief. To take advantage of this, a further drawing designated depth of cut in tenths of a millimetre. The 'print' is 'cast' by spreading on the plate a silicone elastomer (manufactured as a flexible mould material), then reinforcing with a non-woven Terylene cotton fabric". Richard Hamilton.

Today Grossman, a sculptor and Shafiei, an architect use CAD in different ways to realise their three dimensional hybrid forms. The sculptor Bathsheba Grossman uses a laser to cut her CAD drawings into crystal. The points created by a focused laser beam are tiny $(.1 \mathrm{~mm})$ fractures. The conical beam, with a focal length of about $3 "$, shines into the glass without damaging it except at the focal point. At that one point, concentrated energy heats the glass to the cracking point, causing a microfracture.

To draw more points, the laser is pulsed on and off. To make the beam move between points, it is reflected from a mirror that is repositioned between pulses. The mirror is moved by computer-controlled motors, so many points can be drawn with great speed and accuracy. A typical design might use several hundred thousand points, half a million is not unusual in a large block, each placed with .001" accuracy.

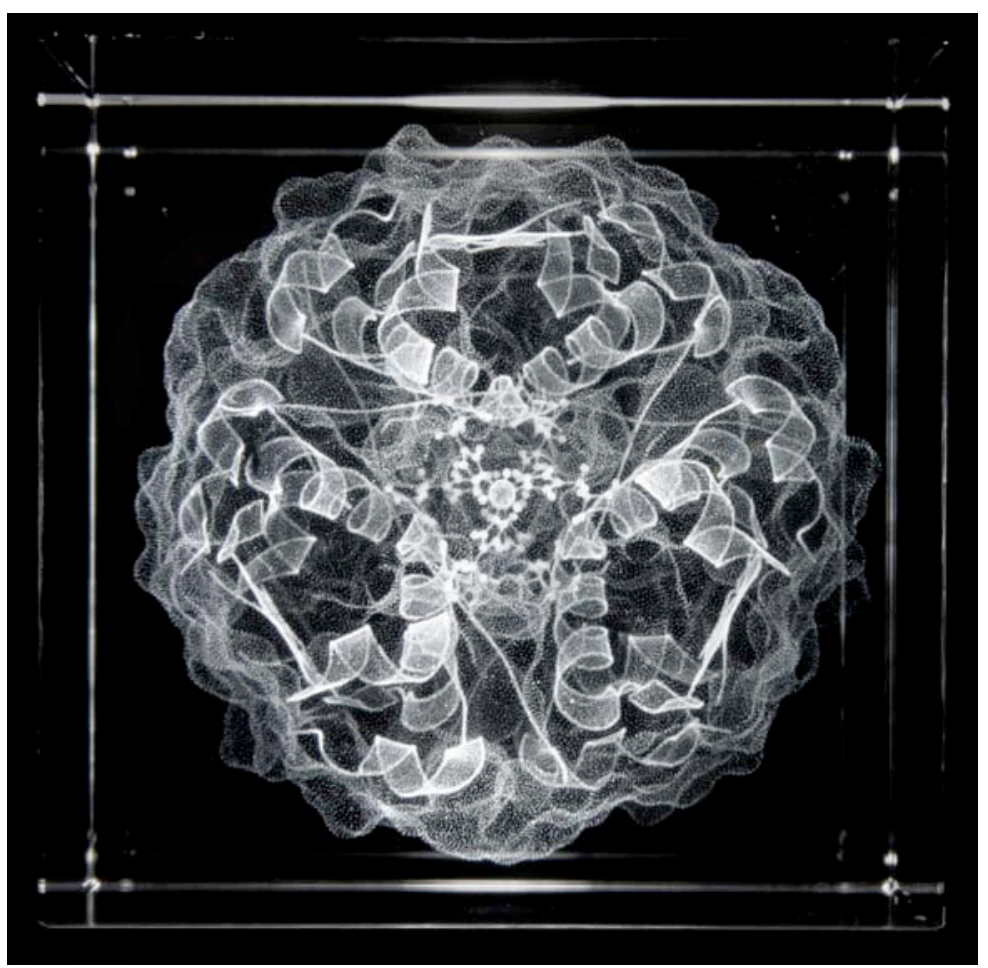

Figure 8. Insulin. Material: jLaser cut crystal block. 2007. Bathsheba Grossman.

The images are produced with different types of laser, and the results vary. Grossman uses a high-frequency laser, which draws points that are barely visible to the naked eye 
using a Nd:YAG laser, named after its active medium: a yttrium-aluminum-garnet crystal doped with neodymium.

The glass itself must be clear optical crystal, since any ripples or bubbles would block or blur the laser. The process requires drawing in layers, moving from the rear to the front of the glass, so that previous points do not block the laser from drawing new ones.

The glass surface must be flat, or refraction will blur and redirect the beam; that is why it is difficult to work with spheres or other curved shapes. Refraction is also an issue in viewing curved glass: in a $60 \mathrm{~mm}$ sphere only the central $20 \mathrm{~mm}$ can be used, because optical magnification makes that area seem to fill the whole sphere. If anything is drawn closer to the surface than that, it will look very distorted.

The architect Sara Shafiei in her project 'Anamorphic Tectonics Theatre for Magicians' plays with the art of illusion, bending laser-cut card. The project is based on a site in the National Botanical Gardens in Rome, and proposes a dispersed magical illusion, with its central spectacle being a theatre for magicians. The building sits at the peak of the site overlooking the gardens. The use of text and cone anamorphosis along with other perspectival illusions, aid in the creation of a landscape of the imagination, which surround the theatre. The project attempts to portray how the foundations of magic and illusion can become an inherent part of an architectural design.

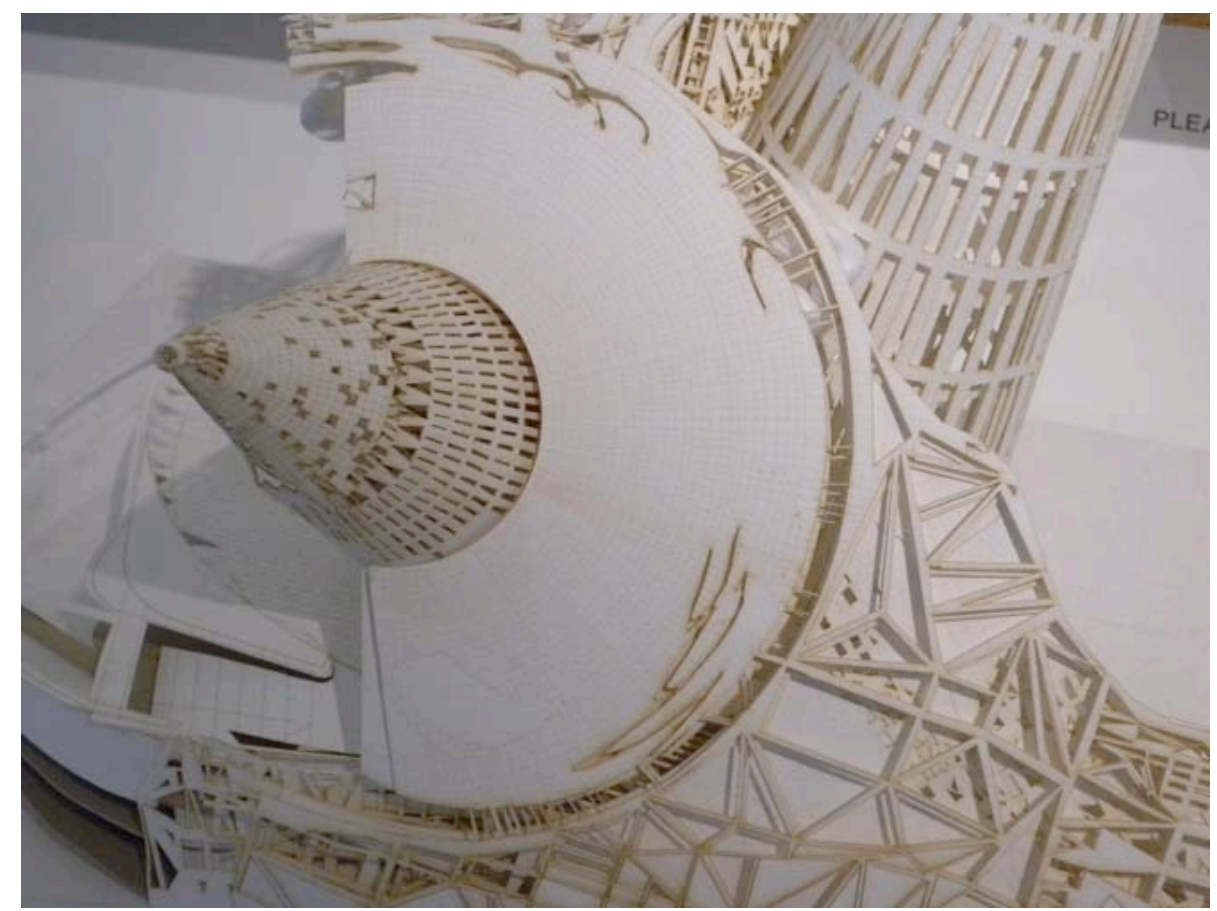

Figure 9. Anamorphic Tectonics: Theatre for Magicians. Laser cut paper, longitudinal section. 2007. Sara Shafiei.

Sara Shafiei explains: "Anamorphosis is a distorted projection or representation of an image on a plane or curved surface, which, when viewed from the correct vantage point, or as reflected space from a curved mirror or through a polyhedron, appears regular and in proportion. This technique takes the form of signs within my architectural proposal. It 
is used in order to allow the visitor to engage with the landscape and architecture and navigate their way through the site. The use of this technique will also allow the visitor to experience a slow progression of a landscape of illusions, from the onset of entering the site."

\section{THE FUTURE}

In 1985 Lisa Phillips, Associate Curator at the Whitney Museum in New York, made the following statement: "So many artists are exploring the computer that it cannot be ignored". But it wasn't until 2001, sixteen years later, that the Whitney Museum acknowledged this aesthetic by organising a major exhibition of Computer Art entitled 'Bitstreams'. Eight years on in 2009 the exhibitions 'Decode' and 'Digital Pioneers' were mounted at the V\&A museum in London.

During the next decade digital craftsmanship will develop and new forms will emerge as solid freeform fabrication becomes more accessible and affordable and artists and designers investigate the many techniques that are available using subtractive and additive processes. This includes developmental research that explores new Rapid Prototyping techniques and processes, e.g. 3D scanning, CNC routing (3 and 5 axis), SLS (Selective Laser Sintering in Nylon), 3D printing and all the new and modified materials that are being developed.

The problems confronting these artists and designers will be the same that faced Mallary and Hamilton in the 1960s. How to consider specific items of technology in terms of what they can do and determine whether or not they are useful and whether or not they allow scope for an idea to be developed or communicated. Another challenge will be whether they can make the technology perform in a certain way even if this contravenes the intentions of its inventors.

\section{References}

[1] BROWN, P and LAMBERT, N and MASON, C and GERE, C (eds.), White Heat and Cold Logic: Early British Computer Art: MIT Press, 2008.

[2] REICHARDT, J. The computer in art. Studio Vista, 1971.

[3] QUINN, B. Scandanavian style. Conran Octopus. 2003.

[4] LASTER, P. Wim Delvoye: Towering ambition. Art in America. 2009.

[5] HAMILTON, R. Collected words. Thames and Hudson. 1982.

[6] GLYNN, R and SHAFIEI, S Digital Architecture, Hinterlands, 2009. 